\title{
Dehumidification of Air Flowing in the Entrance Region of a Channel
}

\author{
R.H. Yeh \\ Department of Marine Engineering and Technology National Taiwan Ocean University \\ W.H. Huang \\ Precision Instrument Development Center National Science Council
}

Follow this and additional works at: https://jmstt.ntou.edu.tw/journal

Part of the Engineering Commons

\section{Recommended Citation}

Yeh, R.H. and Huang, W.H. (1993) "Dehumidification of Air Flowing in the Entrance Region of a Channel," Journal of Marine Science and Technology. Vol. 1: Iss. 1, Article 2.

DOI: $10.51400 / 2709-6998.2472$

Available at: https://jmstt.ntou.edu.tw/journal/vol1/iss1/2

This Research Article is brought to you for free and open access by Journal of Marine Science and Technology. It has been accepted for inclusion in Journal of Marine Science and Technology by an authorized editor of Journal of Marine Science and Technology. 


\title{
DEHUMIDIFICATION OF AIR FLOWING IN THE ENTRANCE REGION OF A CHANNEL
}

\author{
R.H. Yeh* and W.H. Huang** \\ *Department of Marine Engineering and Technology \\ National Taiwan Ocean University \\ **Precision Instrument Development Center \\ National Science Council
}

Key words: dehumidification, entrance, channel.

\begin{abstract}
The heat transfer and dehumidifying characteristics in the entrance region of the parallel plates are studied. Two-dimensional boundary layer equations are solved numerically to obtain the mass concentration for the air-vapor mixture in the inlet of a channel. A simple experiment is conducted to verify the theory. The ratio of the flow length to plate spacing is chosen to be $20 / 3$. It shows that the average total and mass transfer colburn $j$-factors obtained from experimental data are higher than those of numerical analysis. Finally, the relationships between experimental data and numerical results are acquired to facilitate the prospective design of the plate-finned heat exchanger.
\end{abstract}

\section{INTRODUCTION}

Plate-finned heat exchanger is one of the most common types of extended surface heat exchangers. In addition to its wide application in electric power plants, cryogenics, and waste heat recovery systems, the use of air conditioning to ships has become almost universal, because of the increasing proportion of vessels journeying through tropical waters. Even in temperate zones, the heat generated within the ship often requires the provision of air cooling. More and more investigators thereupon are devoted to the study of heat transfer characteristics aswell as dehumidifying process. However, most of the problems considered and in the absence of tubing not because of the hydrodynamic complexity but also the difficulty in generalizing the parameters of tube diameter and spacing.

The plate-finned heat exchanger employed in air conditioning and dehumidifying equipment is designed to reduce the amountof moisture by cooling the flowing air below its dew point so that surplus moisture is precipitated. While techniques exist for the design of heat exchangers chiefly without dehumidification, the design of dehumidifying based on empirical adjustments to the results of dry case, i.e., no condensa- tion occurs.

Assuming laminar flow condition, Guillory [1] developed an analytical model for a dehumidifying flow between parallel plates utilizing the KarmanPohlhausen integral technique. Besides, he also performed an experiment to check the theory. Later on, considering the cleaned, uncleaned, and nonwetting tested surface conditions, McQuiston [2] investigated this problem experimentally. He showed that transition may be delayed by low intensity of free stream turbulence. Kadambi and Giansante [3] predicted the local heat and mass transfer coefficient as well as pressure drops for flow between flat plates analytically, assuming that the condensed liquid flows as a laminar film unaffected by gravity.

It is known that deposition of moisture on the surface of the exchanger (as drops, a wavy film or combinations of the two)may disturb the boundary layer. Thus for a given temperature difference, a finned evaporator will operate effectively if dehumidification occurs simultaneously. The objective of this study is to investigate numerically and experimentally the performance of a simplified common plate-finned evaporator. The numerical analysis is made to predict the local heat and mass transfer coefficients as well as pressure drops for flow in a channel. 
In addition, the experimental data are compared and correlated with the numerical results.

\section{THEORETICAL ANALYSIS}

Consider a humid air flowing between parallel flat plates. In order to make parametric studies possible, some assumptions are made as follows:

1. constant fluid properties.

2. steady, two-dimensional laminar flow.

3. constant wall temperature (below the dew point of the mixture but above the frost point):

4. uniform velocity, temperature, and moisture concentration in the entry.

5. no effects due to condensate deposition.

6. neglecting buoyancy and viscous dissipation effect.

7. ideal gas behavior of air.

In applications, the temperatures of gases and airvapor mixtures are always in the range between $125^{\circ} \mathrm{F}$ and the frost point. It is reasonable to assume Lewis number to be unity for air-vapor mixture [4]. Also with the usual Prandtl boundary layer assumption, the following dimensionless parameters are employed

$$
\begin{array}{ll}
\mathrm{U}=\frac{\mathrm{u}}{\mathrm{u}_{0}} & \mathrm{~V}=\frac{\mathrm{v}}{\mathrm{u}_{0}} \\
\mathrm{X}=\frac{\mathrm{X}}{\mathrm{b}} & \mathrm{Y}=\frac{\mathrm{y}}{\mathrm{b}} \\
\mathrm{P}=\frac{\mathrm{p}-\mathrm{p}_{0}}{\rho \mathrm{u}_{0}} & \mathrm{M}=\frac{\mathrm{m}-\mathrm{m}_{0}}{\mathrm{~m}_{\mathrm{w}}-\mathrm{m}_{0}} \\
\mathrm{I}=\frac{\mathrm{i}-\mathrm{i}_{0}}{\mathrm{i}_{\mathrm{w}}-\mathrm{i}_{0}} & \theta=\frac{\mathrm{t}-\mathrm{t}_{0}}{\mathrm{t}_{\mathrm{w}}-\mathrm{t}_{0}}
\end{array}
$$

the continuity, momentum, energy, and mass concentration equations are normalized in the following forms

$$
\begin{aligned}
& \frac{\partial U}{\partial X}+\frac{\partial V}{\partial Y}=0 \\
& \mathrm{U} \frac{\partial \mathrm{U}}{\partial \mathrm{X}}+\mathrm{V} \frac{\partial \mathrm{U}}{\partial \mathrm{Y}}=-\frac{\partial \mathrm{P}}{\partial \mathrm{X}}+\frac{1}{\operatorname{Re}} \cdot \frac{\partial^{2} \mathrm{U}}{\partial \mathrm{Y}^{2}} \\
& \mathrm{U} \frac{\partial \mathrm{I}}{\partial \mathrm{X}}+\mathrm{V} \frac{\partial \mathrm{I}}{\partial \mathrm{Y}}=\frac{1}{\operatorname{ScRe}} \cdot \frac{\partial^{2} \mathrm{I}}{\partial \mathrm{Y}^{2}} \\
& U \frac{\partial M}{\partial X}+V \frac{\partial M}{\partial Y}=\frac{1}{S c R e} \cdot \frac{\partial^{2} M}{\partial Y^{2}}
\end{aligned}
$$

For dry case, i.e., no condensation on the plates, Eqs. (3) and (4) will be replaced by

$$
\mathrm{U} \frac{\partial \mathrm{U}}{\partial \mathrm{X}}+\mathrm{V} \frac{\partial \theta}{\partial \mathrm{Y}}=\frac{1}{\operatorname{PrRe}} \cdot \frac{\partial^{2} \theta}{\partial \mathrm{Y}^{2}}
$$

As for the boundary conditions, they are nondimensionalized as

$$
\begin{array}{ll}
\mathrm{X}=0 & \mathrm{U}=1, \mathrm{~V}=0, \mathrm{I}=0, \mathrm{M}=\theta=0 \\
\mathrm{Y}=0 & \frac{\partial \mathrm{U}}{\partial \mathrm{Y}}=\frac{\partial \mathrm{V}}{\partial \mathrm{Y}}=\frac{\partial \mathrm{I}}{\partial \mathrm{Y}}=\frac{\partial \mathrm{M}}{\partial \mathrm{Y}}=\frac{\partial \theta}{\partial \mathrm{Y}}=0 \\
\mathrm{Y}=1 & \mathrm{U}=0, \mathrm{~V}=0, \mathrm{I}=1, \mathrm{M}=\theta=1
\end{array}
$$

Since the momentum, energy, and mass concentration equations are all in parabolic type of partial differential equations, the method of Gaussian elimination was used to obtain the solutions.

The Colburn $j$-factors can be obtained from energy and mass continuity balance across the test heat exchanger. The total heat transfer $j$-factor $j_{i}$ is defined as

$$
\mathrm{j}_{\mathrm{i}}=\operatorname{Pr}^{2 / 3} \cdot(\mathrm{b} / \mathrm{L}) \cdot \ln \left(\frac{\dot{\mathrm{i}}_{\text {in }}-\mathrm{i}_{\mathrm{w}}}{\dot{i}_{\text {out }}-\mathrm{i}_{\mathrm{w}}}\right)
$$

It can be obtained from the energy balance

$$
h_{i} A \cdot \Delta i=m\left(i_{\text {in }}-i_{\text {out }}\right)
$$

and $i_{m}$ is a $\log$ mean enthalpy difference, i.e.

$$
\Delta i=\frac{\left(i_{\text {in }}-i_{\text {out }}\right)}{\ln \left(\frac{i_{\text {in }}-i_{w}}{i_{\text {out }}-i_{w}}\right)}
$$

It is noted that all enthalpies in the above equation are mean values. In an analogous manner, the sensible heat transfer $j$-factor is given as

$$
j_{t}=\operatorname{Pr}^{2 / 3} \cdot(b / L) \cdot \ln \left(\frac{t_{\text {in }}-t_{w}}{t_{\text {out }}-t_{w}}\right)
$$

and the mass transfer $j$-factor $j_{m}$ is defined as

$$
\mathrm{j}_{\mathrm{m}}=\mathrm{Sc}^{2 / 3} \cdot(\mathrm{b} / \mathrm{L}) \cdot \ln \left(\frac{\mathrm{m}_{\mathrm{in}}-\mathrm{m}_{\mathrm{w}}}{\mathrm{m}_{\text {out }}-\mathrm{m}_{\mathrm{w}}}\right)
$$

The total Nusselt number concerning both the sensible and latent heat transfer is thus written as

$$
N u_{i}=P e \cdot(b / L) \cdot \ln \left(\frac{i_{\text {in }}-i_{w}}{i_{\text {out }}-i_{w}}\right)
$$

where $\mathrm{Pe}$ is a Peclet number. 


\section{EXPERIMENTAL APPARATUS AND PROCEDURES}

A wind tunnel of Hilton A572 was modified and used in this experiment. It was powered by a $120 \mathrm{~W}$ centrifugal fan with variable speed control. The air flow in the entry of the test section was made to be approximately uniform with the aid of many layers of screen. The test heat exchanger is a parallel-plate box as given in Fig. 1 having a length of $45 \mathrm{~cm}$, a width of $25 \mathrm{~cm}$, and a depth of $20 \mathrm{~cm}$. Six parallel plates with a thickness of $1 \mathrm{~cm}$ in each were designed with sharp leading edges to minimize the intensity of turbulence. The uniform wall temperature was achieved by chilled water circulating between the parallel-plate box and chiller at a flowrate of $61 \mathrm{1} / \mathrm{min}$. Six $K$-type thermocuples were employed to record the inlet and outlet temperatures of the flowing air, chilled water, and the plate-wall. In addition, two wet bulb thermometers were placed upstream and downstream of the test section.

Before each experimental run, the surfaces of the stainless plate walls were cleaned carefully with alcohol. Initially, start the chilled water circulating pump until all the air in the pipe was driven out, then turned on the chiller. The wind speed is controlled by adjusting the voltage input to the fan motor. Tests were considered to be steady state when all the temperature readings changed less than $0.2^{\circ} \mathrm{C}$ in five minutes. In addition, while testing, the local atmospheric pressure is measured and recorded.

\section{DATA REDUCTION}

The relevant important parameters have been

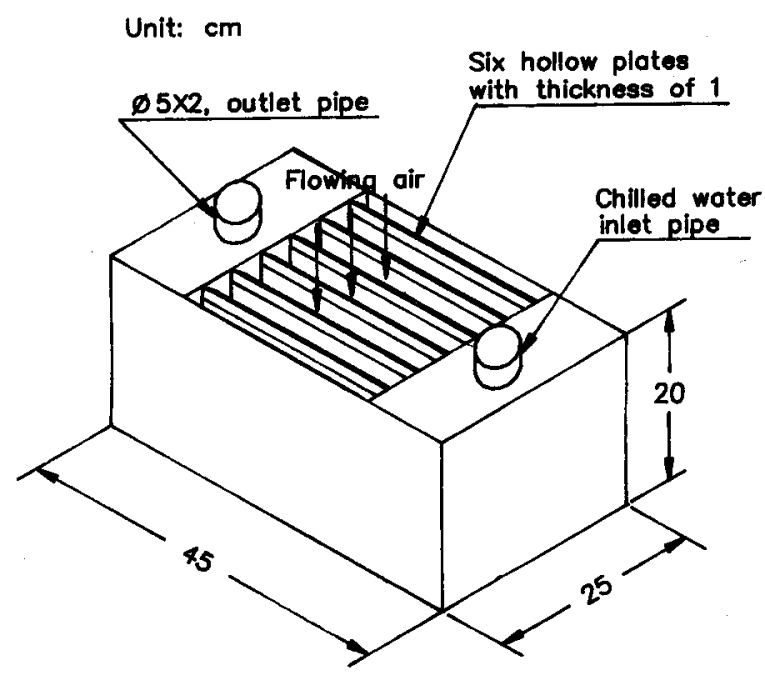

Fig. 1. The test parallel-plate box. theoretically introduced in Equations (9), (12), (13), and (14). However, those are all based on the assumptions of constant wall temperature. In the present experiment, though a high flow rate of cooling water is designed, the temperature of wall plates still hardly remain constant. This is mainly the reason that the total heat flux between the water and the air is quite different at the inlet and outlet of the exchanger due to different driving potentials and developing boundary layer effects. The total $j$-factor is then obtained as

$$
j_{i}=\operatorname{Pr}^{2 / 3}(b / L) \cdot\left(\frac{\left(i_{\text {in }}-i_{\text {out }}\right)}{\Delta i_{m}}\right)
$$

where $i_{m}$ has the form below

$$
\Delta i_{m}=\frac{\left(i_{\text {in }}-i_{w i}\right)-\left(i_{\text {out }}-i_{w 0}\right)}{\ln \left(\frac{i_{\text {in }}-i_{w i}}{i_{\text {out }}-i_{\text {wo }}}\right)}
$$

In the same manner, the $j_{t}, j_{m}$, and $\mathrm{Nu}_{\mathrm{i}}$ thus becomes

$$
\begin{aligned}
& \mathrm{j}_{\mathrm{t}}=\operatorname{Pr}^{2 / 3} \cdot(\mathrm{b} / \mathrm{L}) \cdot\left(\frac{\left(\mathrm{t}_{\text {in }}-\mathrm{t}_{\text {out }}\right)}{\Delta \mathrm{t}_{\mathrm{m}}}\right) \\
& \mathrm{j}_{\mathrm{m}}=\mathrm{Sc}^{2 / 3} \cdot(\mathrm{b} / \mathrm{L}) \cdot\left(\frac{\mathrm{m}_{\text {in }}-\mathrm{m}_{\text {out }}}{\Delta \mathrm{m}_{\mathrm{m}}}\right)
\end{aligned}
$$

and

$$
N u_{i}=P e \cdot(b / L) \cdot\left(\frac{\left(i_{\text {in }}-i_{\text {out }}\right)}{\Delta i_{m}}\right)
$$

\section{RESULTS AND DISCUSSION}

In a preparatory work, the accuracy of the present numerical analysis was checked. The fanning friction factor and $j_{i, m}$ factors obtained by previous analytical studies $[1,3]$ are calculated. Figure 2 displays the results of the comparison. It is observed that most analytical results are in good accord with the present numerical calculation.

In this study, the parallel plates with a spacing of $3 \mathrm{~cm}$ and $20 \mathrm{~cm}$ in flow length is selected to be analyzed numerically and experimentally. Figure 3 shows the comparison between the experimental $j_{i}$ factors with numerical predictions. The test data fall above the predicted curve because droplet formation tends to trip the stream into a very turbulent motion. In addition, large disagreement is found due to the assumption of laminar flow. Apparently, the moisture deposition significantly affects the flow regime.

The results of numerical and experimental calculations of the $j$-factor based on concentration potential are shown in Fig. 4. In general, same trends in the previous 


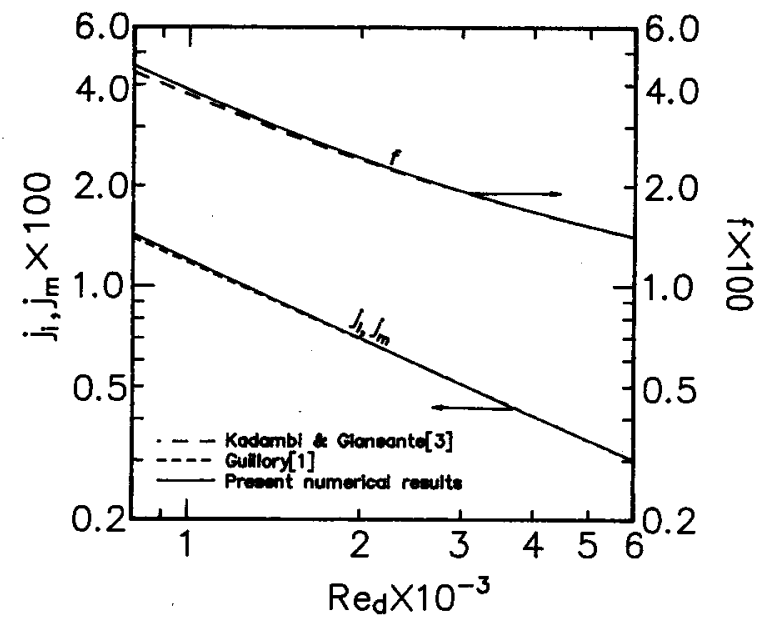

Fig. 2. Comparison of the present numerical results with previous works.

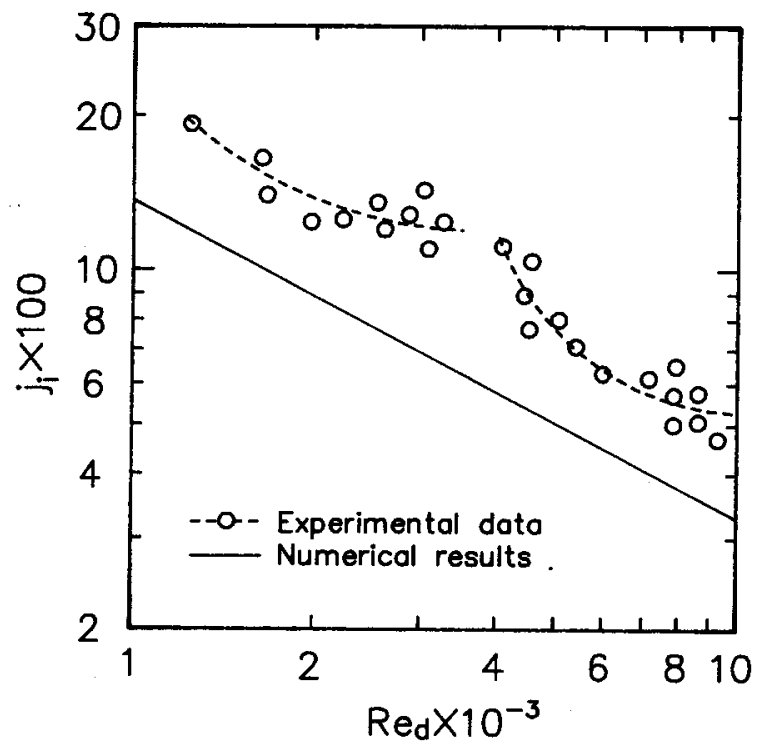

Fig. 3. Dependence of $j_{i}$ on Red.

discussion of the total $j$-factor apply to this case. Since the flow disturbance is a factor in mass transfer rates, the condensate deposition will not be the major contributor to the increase of $j_{m}$. In turbulent region, $j_{m}$ decreases more rapidly than the numerical prediction than $j_{i}$.

The dimensionless factor

$$
\phi=\frac{\omega_{\text {in }}+\omega_{\text {out }}}{\omega_{\mathrm{w}}}
$$

is advantageous in physical significance. It approaches unity for dry air whereas a larger value of $\phi$ represents a greater potential for mass diffusion as well as a greater latent load. Since $\phi$ varies with boundary conditions andthe operating Reynolds number, each

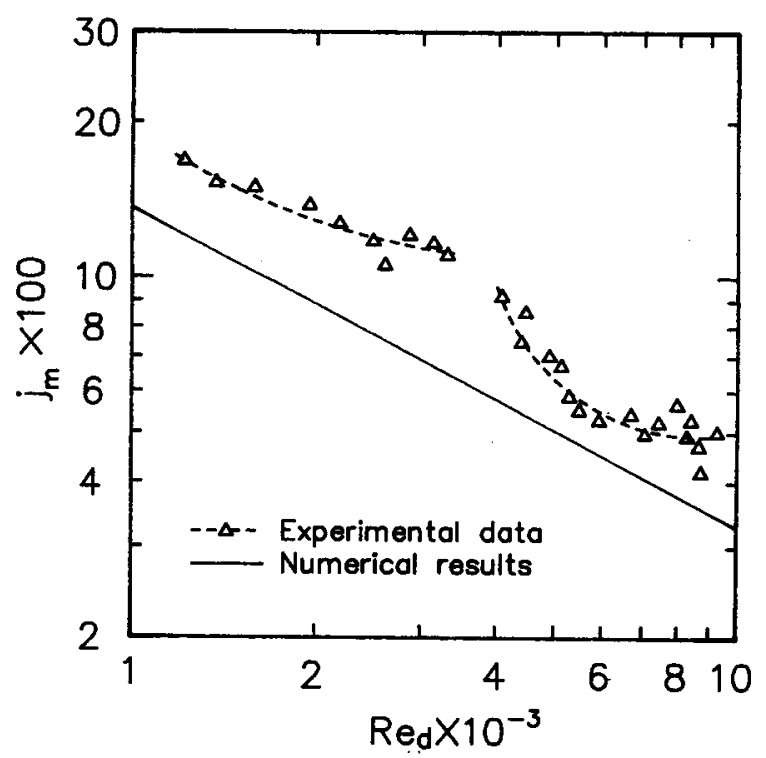

Fig. 4. Dependence of $j_{m}$ on Red.

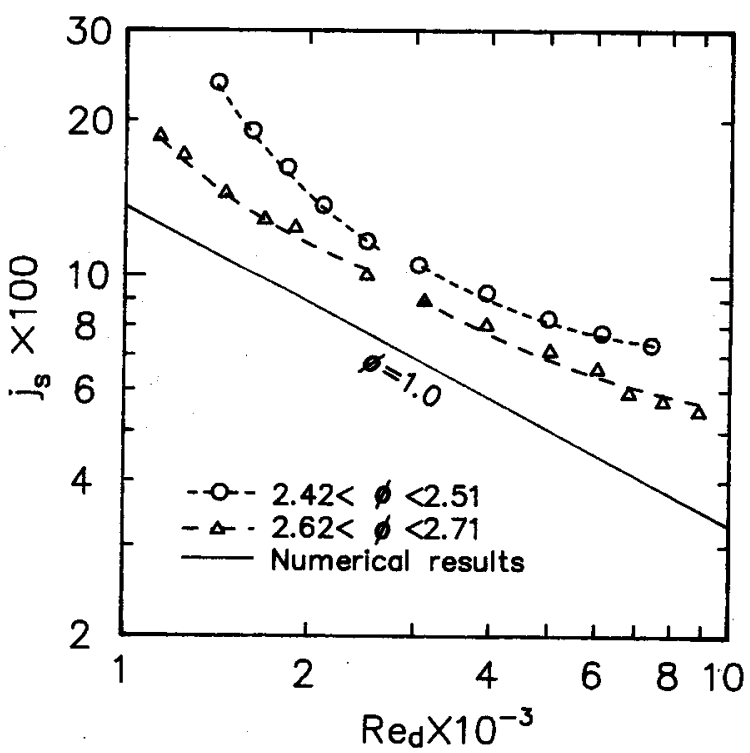

Fig. 5. Dependence of $j_{s}$ on Red.

line of constan $\phi$ has relatively few data on it. It is usual to select a range of values of this parameter which, on the average, stands for some desired values of $\phi$. However, this relation is not continuous for $1<$ $\phi<\infty$ due to the disturbance of boundary layer caused by moisture deposition.

Figure 6 depicts the variation of the mean Nusselt number in the inlet of a channel. The discussion concerning $N u_{i}$ is not significantly different from those of the total $j$-factor. The results of the experiment conducted by Guillory[1] with a ratio, 24:1, of flow length to plate spacing is given in Fig. 7 for comparison. It is seen that the experimental data fall close to the numerical prediction for larger $L /(2 \mathrm{~b})$ 


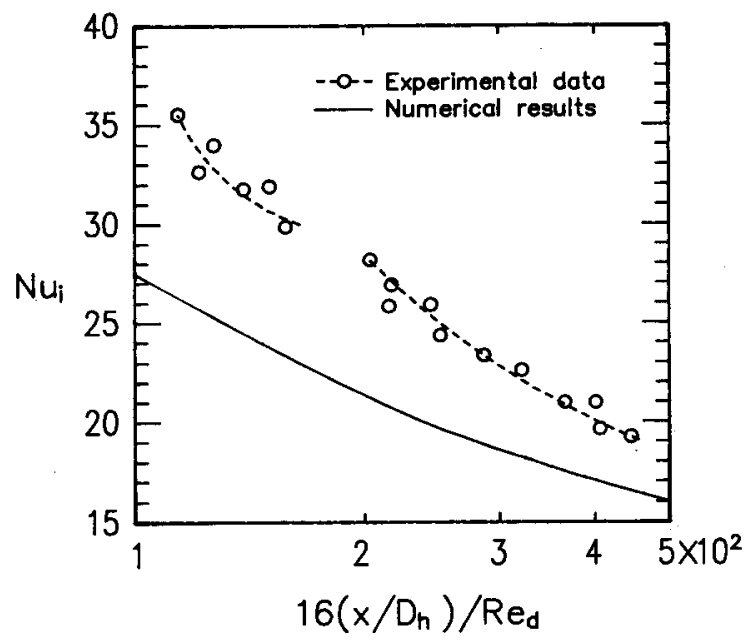

Fig. 6. The variation of Nusselt number in the inlet of a channel.

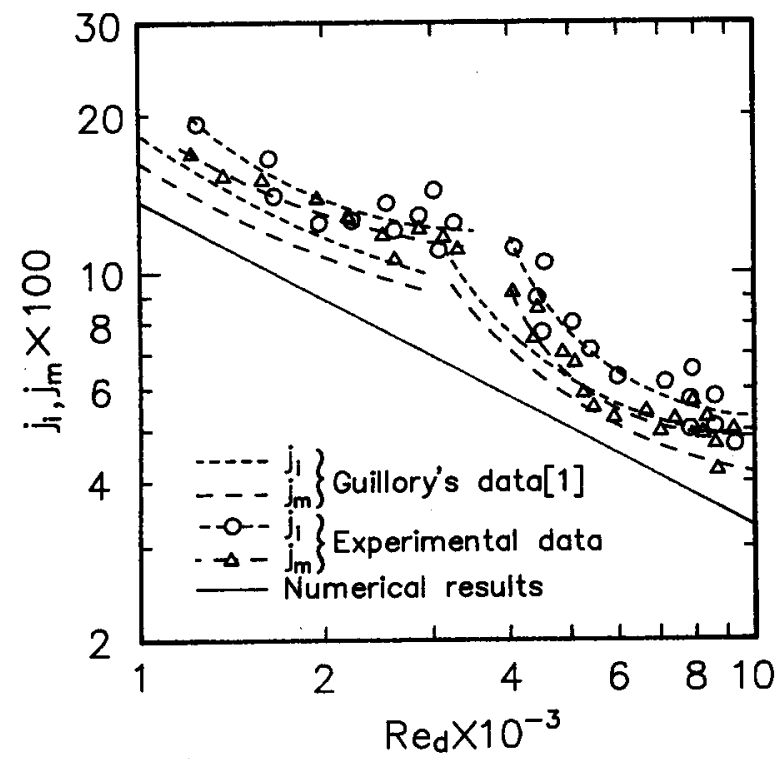

Fig. 7. Comparison of the present study with previous work.

ratios. It should be noted that still few data for other $L /(2 \mathrm{~b})$ ratios and the operating Reynolds number under 1000 .

\section{CONCLUSIONS}

The heat transfer and dehumidifying characteristics in the entrance region of a channel are studied. For a common use of the data of the exchanger with $L /$ (2b) ratio of $20: 3$, some modifications are made in the following:

For the dehumidifying parallel heat exchanger, $j_{i}$ and $j_{m}$ can be correlated as

$$
\begin{aligned}
& \frac{\mathrm{j}_{\mathrm{i}}(\text { experiment })}{\mathrm{j}_{\mathrm{i}} \text { (theory) }}=0.862+0.086 \cdot \ln \left(\mathrm{Re}_{\mathrm{d}}\right) \\
& 1000<\mathrm{Re}_{\mathrm{d}}<3000
\end{aligned}
$$

and

$$
\begin{aligned}
& \frac{\mathrm{j}_{\mathrm{m}} \text { (experiment) }}{\mathrm{j}_{\mathrm{m}} \text { (theory) }}=-2.11+0.484 \cdot \ln \left(\mathrm{Re}_{\mathrm{d}}\right) \\
& 1000<\mathrm{Re}_{\mathrm{d}}<3000
\end{aligned}
$$

respectively, in the laminar region. For the turbulent region the correlations are

$$
\begin{aligned}
& \frac{\mathrm{j}_{\mathrm{i}}(\text { experiment })}{\mathrm{j}_{\mathrm{i}}(\text { theory })}=5.865-0.495 \cdot \ln \left(\mathrm{Re}_{\mathrm{d}}\right) \\
& 4000<\mathrm{Re}_{\mathrm{d}}<10000
\end{aligned}
$$

and

$$
\begin{aligned}
& \frac{\mathrm{j}_{\mathrm{m}}(\text { experiment })}{\mathrm{j}_{\mathrm{m}}(\text { theory })}=6.637+0.586 \cdot \ln \left(\mathrm{Re}_{\mathrm{d}}\right) \\
& 4000<\mathrm{Re}_{\mathrm{d}}<10000
\end{aligned}
$$

\section{NOMENCLATURES}

$A=$ free flow area

$b=$ half plate spacing

$I=$ dimensionless enthalpy

$i=$ enthalpy

$j=$ Colburn $j$-factor

$L=$ flow length

$L e=$ Lewis number, $\mathrm{Pr} / \mathrm{Sc}$

$M=$ dimensionless concentration

$m=$ concentration

$\mathrm{Nu}=$ Nusselt number

$P=$ dimensionless pressure

$P e=$ Peclet number, $\operatorname{RePr}$

$P r=$ Prandtl number

$p=$ pressure

$R e=$ Reynolds number

$S c=$ Schmidt number

$t=$ temperature

$U, V=$ dimensionless velocity

$u=$ local velocity component in flow direction

$v=$ local velocity component normal to flow direct -ion.

$X, Y=$ dimensionless coordinate

$x=$ coordinate along channel

$\mathrm{y}=$ coordinate across channel

$\theta=$ dimensionless temperature

$\rho=$ density 
$\phi=$ dimensionless parameter defined in Eq.(20)

$\omega=$ specific humidity

\section{Subscripts}

$d=$ hydraulic

$i=$ total

in $=$ inlet

$m=$ mass transfer; log mean

$o=$ entrance; stagnation

out $=$ outlet

$t=$ sensible

$w=$ wall

\section{REFERENCES}

1. Guillory, J.L.,Dehumidification of Air Flowing Between Parallel Plates, Ph.D. Thesis, Oklahoma State University, Oklahoma, (1973).

2. McQuiston, F.C.,"Heat, Mass, and Momentum Transfer in a Parallel Plate Dehumidifying Exchanger",ASHRAE Trans., Vol. 82, pp. 87-106 (1976)

3. Kadambi,V.and Giansante, J.E., "Dehumidification Between Parallel Plates", ASHRAE Trans., Vol. 93, pp. 255-267(1982).

4. Kays, W.M. and Crawford, M.E., Convective Heat and Mass Transfer, 2nd edition, McGraw-Hill, New York, (1980). 